\title{
Editorial
}

\section{Social Media in Ophthalmology: The Educational and Professional Potential for Medical Students}

\author{
Gabriella Schmuter, BS ${ }^{1}$ Andrea A. Tooley, MD ${ }^{2,3}$ \\ ${ }^{1}$ The City University of New York School of Medicine, New York, New \\ York \\ ${ }^{2}$ Department of Ophthalmology, Columbia University, New York, \\ New York \\ ${ }^{3}$ Department of Ophthalmology, Mayo Clinic, Rochester, Minnesota \\ ${ }^{4}$ Department of Ophthalmology and Visual Sciences, Vanderbilt Eye \\ Institute, Nashville, Tennessee
}

J Acad Ophthalmol 2020;12:e41-e45.

With the recent rise of social media usage, ${ }^{1}$ it is becoming imperative to discuss its role in ophthalmology. Several articles exist to lay out guidelines surrounding social media use for ophthalmologists ${ }^{2,3}$ and medical professionals overall. ${ }^{4-6}$ The role that social media plays in providing medical students with greater exposure to smaller fields, such as ophthalmology, is often overlooked.

As a medical student at a newly established medical school, I (G.S.) have found it challenging to gain exposure to the field without the presence of an ophthalmology department or residency to give guidance. Fortunately, social media has been an effective source for finding enthusiastic mentors, discovering research opportunities, and learning about ophthalmology at large. For example, I found a lot of practical and meaningful advice in Dr. Andrea Tooley's YouTube ${ }^{7}$ and Instagram $^{8}$ accounts, which documented Dr. Tooley's medical journey from medical school into her present fellowship. I was able to cultivate a passion for ophthalmology early in the first year of medical school through following various ophthalmology social media accounts, which guided me toward research opportunities and experiences with the intention of becoming a competitive applicant in the match.

Although the benefits of social media are largely anecdotal, the aim of this editorial is to describe the value that social media produces for medical students who are interested in exploring ophthalmology as a community and as a profession. This is particularly critical for students who do not have the institutional resources to extend experiences pertinent to the field. The authors ultimately believe that effective use of social media by both ophthalmologists and medical students will inspire more talented students to realize their passions within the field earlier. We additionally wish to offer guidance to medical students regarding potential risks of social media in professional use.

\author{
Royce W. S. Chen, MD ${ }^{2}$ Janice C. Law, MD
}

\section{The Limits of Medical School Curricula}

Medical school curricula are highly variable and often limited in offering students education and/or exposure to ophthalmology. ${ }^{9}$ Additional medical school opportunities in ophthalmology are often carved out by students who already possess an underlying interest in the field. ${ }^{10}$ Since the San Francisco Match ${ }^{11}$ takes place considerably early compared with the National Resident Matching Program ${ }^{12}$ for other specialties, it is particularly important for medical students to identify their interest in ophthalmology as early as possible to get a head start in building experiences necessary to become competitive candidates.

Previous studies have reported medical students lacking in ophthalmologic knowledge ${ }^{13}$ or lacking proficiency in basic ocular examination skills. ${ }^{14}$ Incorporating focused training and clinical opportunities in ophthalmology can be inherently challenging for medical schools with otherwise established curricula and/or limited time and resources.

More challenges might occur if an institution lacks an ophthalmology department or residency program, as I encountered in my medical school career. The presence of an ophthalmology residency in medical school has been found to be a significant predictor of matching, and a majority of students who match into ophthalmology attend programs in the same geographic area as their medical school. ${ }^{15}$ Medical students who have strong ophthalmology departments may be at a particular advantage for finding resources to strengthen their applications and build connections within the field. It is possible that some residency programs demonstrate some inherent preference toward matching medical students who come from their own institution. It is therefore crucial for medical students at institutions that lack ophthalmology departments to demonstrate greater initiative in independently seeking out

Copyright $\odot 2020$ by Thieme Medical Publishers, Inc., 333 Seventh Avenue, New York, NY 10001, USA. Tel: +1(212) 760-0888.

\section{License terms

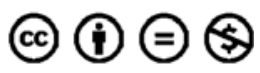


opportunities and connections in ophthalmology from more unconventional outlets, such as through social media.

Although the effect of social media in graduate medical education is inconclusive, ${ }^{16}$ we argue that the use of social media in ophthalmology by medical students has potential to improve their training experience and increase access to opportunities in a way that can be feasibly integrated into their busy schedules.

\section{Opportunities in Ophthalmology on Social Media}

Professional ophthalmologist accounts on platforms such as Instagram provide medical students with insight into the clinical situations that are commonly encountered in practice. In particular, the use of video recording in ophthalmic surgery has broadened the ability to deliver informal educational content through social media. ${ }^{17}$ Many social media Web sites provide links to ophthalmic video resources through YouTube or Eyetube. Eyetube supplies videos of ophthalmic surgery grouped by subspecialty and additionally allow registered viewers to comment and rate the quality of the videos. ${ }^{18,19}$ Ophthalmology accounts on social media present medical students with streamlined awareness of recent news in the field that they perhaps would not have encountered otherwise. For example, the Twitter account of the journal Ophthalmology (@AAOjournal) currently provides more than 6,000 followers with images and links to recent ophthalmic publications and updates. ${ }^{20}$ Additionally, there are ophthalmology Web sites that are specifically geared toward students who may seek a foundation in ophthalmology, and social media accounts may be used to increase awareness of such resources. By sharing the links to educational Web sites in ophthalmology on social media platforms, a larger number of students would learn about the utility of such resources. For example, Dr. Timothy Root operates an educational Web sites as the "Virtual Eye Professor," where he uploaded eye training videos and other relevant content about ocular pathology, providing simple and straightforward explanations for students. ${ }^{21}$ Such Web sites are particularly useful when students are not sure how to begin building foundational knowledge in the field. Recommended resources and examples with descriptions of their implications for medical students are listed in - Table $\mathbf{1}$.

Moreover, social media serves as networking tools, providing medical students with forums to discover mentors within ophthalmology. The Association of University Professors of Ophthalmology (AUPO) Facebook page (@aupo.org) presents followers with awareness of various AUPO conferences. ${ }^{22}$ Ophthalmologists frequently collaborate through social media-for example, in a survey of surgical retina attendings at a Young Retina Forum, 98 out of 100 respondents agreed that the social media outlet Telegram was useful for networking and discussion. ${ }^{23}$ Ophthalmologists at varying stages in their careers can extend different perspectives on processes such as residency match to medical students through social media, and such access to mentorship can be pivotal for students at medical schools that lack ophthalmology departments. Additionally, mentorship through social media eliminates geographic barriers by allowing medical students to maintain

Table 1 List of social media resources along with their classification and various examples

\begin{tabular}{|c|c|c|c|}
\hline Resource & Type & Examples & Practical uses for medical students \\
\hline Eyetube & $\begin{array}{l}\text { Surgical video } \\
\text { resource }\end{array}$ & $\begin{array}{l}\text { Example of videos: } \\
\text { - Piercing the Darkness-Cataract } \\
\text { Surgery on a Blind Eye }\end{array}$ & $\begin{array}{l}\text { - Increasing educational exposure to } \\
\text { procedures and practices in } \\
\text { ophthalmology }\end{array}$ \\
\hline YouTube & $\begin{array}{l}\text { Video sharing } \\
\text { Web site }\end{array}$ & $\begin{array}{l}\text { Examples of channels: } \\
\text { - Ophthalmology Times } \\
\text { - EyeSmart-American Academy } \\
\text { of Ophthalmology } \\
\text { - JAMA Ophthalmology }\end{array}$ & $\begin{array}{l}\text { - Increasing educational exposure to } \\
\text { procedures and practices in ophthalmology } \\
\text { - Informal advice and tips for students } \\
\text { - Updates on latest news in the field }\end{array}$ \\
\hline Instagram & $\begin{array}{l}\text { Photo and video } \\
\text { sharing social } \\
\text { networking site }\end{array}$ & $\begin{array}{l}\text { Examples of account handles: } \\
\text { - Women in Ophthalmology } \\
\text { (@womeninophthalmology) } \\
\text { - Ophthalmology Today } \\
\text { (@ophthalmologytoday) }\end{array}$ & $\begin{array}{l}\text { - Informal advice and tips for students } \\
\text { - Updates on latest news in the field } \\
\text { - Exploring research opportunities } \\
\text { - Seeking out mentorship }\end{array}$ \\
\hline Twitter & $\begin{array}{l}\text { Microblogging } \\
\text { social networking site }\end{array}$ & $\begin{array}{l}\text { Examples of account handles: } \\
\text { - Ophthalmology (@AAOjournal) } \\
\text { - The Ophthalmologist (@OphthoMag) } \\
\text { - JAMA Ophthalmology (@JAMAOphth) }\end{array}$ & $\begin{array}{l}\text { - Links to latest research and updates } \\
\text { in the field } \\
\text { - Exploring research opportunities } \\
\text { and conferences }\end{array}$ \\
\hline Linkedln & $\begin{array}{l}\text { Professional } \\
\text { employment-oriented } \\
\text { social networking site }\end{array}$ & $\begin{array}{l}\text { Examples of pages: } \\
\text { - American Academy of Ophthalmology }\end{array}$ & $\begin{array}{l}\text { - Seeking out mentorship } \\
\text { - Updates on latest news in the field }\end{array}$ \\
\hline Facebook & $\begin{array}{l}\text { Social networking } \\
\text { Web site }\end{array}$ & $\begin{array}{l}\text { Examples of pages: } \\
\text { - Association of University Professors } \\
\text { of Ophthalmology (@aupo.org) } \\
\text { - American Academy of Ophthalmology } \\
\text { (@AmericanAcademyofOphthalmology) }\end{array}$ & $\begin{array}{l}\text { - Links to latest research and updates } \\
\text { in the field } \\
\text { - Exploring research opportunities } \\
\text { and conferences }\end{array}$ \\
\hline
\end{tabular}

Note: The practical uses of such Web sites and applications for medical students are overlapping and are not limited to those listed in the table. 
successful long-distance communication across the globe to share ideas and discuss topics pertinent to the field.

Ophthalmologists on social media may additionally contribute insights regarding career objectives, including leadership and teaching, that can inspire a medical student to consider engaging in a career of academic research, medical education, and/or advocacy. It is valuable for a medical student to foster a generic sense of what scope of practice he or she may wish to engage in, as such factors may help a student make more informed and calculated decisions regarding research opportunities, mentors, residency applications, and beyond. Ophthalmologists frequently use social media as a tool to shed light on pressing issues within ophthalmology and offer opportunities for advocacy within the field, such as through the American Academy of Ophthalmology's (AAO) Advocacy Ambassador Program. ${ }^{24}$ For example, the 2019 AAO Mid-Year Forum, a major annual meeting to advocate for health care policies affecting ophthalmology, ${ }^{25}$ was widely broadcasted on Twitter to those who followed the hashtag \#MyF2019. ${ }^{26}$ By following such forums online, students can engage with leading mentors who possess similar passions to support causes affecting the field.

Medical students may initially discover different social media accounts in ophthalmology using the search function available on many platforms. Many social media accounts frequently use hashtags to categorize their content appropriately and allow accounts to easily discover their posts. Searching generic ophthalmology buzzwords on social media will lead students to major ophthalmology accounts with frequent updates and a large following. It is also useful for students to scroll through the list of followers under a specific account, as it is typical for ophthalmology accounts to follow others who produce similar content. It is through such exploration that a student comes to encounter a large variety of ophthalmology profiles to choose from and to follow. Likewise, we do encourage current ophthalmology accounts to make ample use of hashtags to clearly categorize their content. Using broad hashtags (e.g., health or medicine) on posts has the potential to reach a wide audience and subsequently reaches other health professional students. Ophthalmology accounts are also encouraged to list their medical subspecialty or academic titles clearly on profiles so that students may efficiently determine if an account is geared toward their particular interests or goals.

It is apparent that several factors, including United States Medical Licensing Examination board scores and involvement in research, impact competitiveness for ophthalmology residency. ${ }^{27}$ Strategizing one's approach for ophthalmology match is advantageous as ophthalmology remains as a highly selective medical specialty. Increasing the overall exposure to ophthalmology within medical schools can attract more driven students to enter the field. If students develop their interests in ophthalmology earlier, they will have more ample time to develop their applications and build meaningful connections within the field, which may ultimately strengthen the overall candidate pool for ophthalmology residencies.
Notably, diversity in the ophthalmology workforce is lacking, ${ }^{28}$ and it is possible that social media may equalize opportunities for all students to explore the field. Social media use is not limited by race, gender, sexual orientation, geographical barriers, medical school ranking, or other factors that may directly or indirectly impact opportunities to access resources in ophthalmology. Of course, the amount of time an individual spends on social media is entirely a personal choice. Social media use is not ubiquitous among all medical students-many intentionally choose to not engage in any social media, and therefore, may not encounter such opportunities in ophthalmology in this regard. The ethnic and socioeconomic diversity of residency applicant pools in ophthalmology can grow by spreading awareness of opportunities in the field on uniform platforms that are accessible to all, such as through social media. Additionally, current programs specifically aimed at increasing underrepresented minorities in ophthalmology, such as the Minority Ophthalmology Mentoring program provided by the AAO and $\mathrm{AUPO},{ }^{29}$ can be broadcasted through social media platforms to increase their applicant pool and encourage student interest. Seeking out mentors through social media may be particularly effective for students who wish to take guidance from ophthalmologists of similar personal backgrounds.

\section{Caveats for Medical Students on Social Media}

Although the benefits of social media are obvious, there are some important pitfalls of which one needs to be aware. Medical students, like all physicians, need to be mindful of the messages relayed by their social media accounts from both professional and legal perspectives. Ophthalmologists are urged to consider creating separate accounts for professional and personal use ${ }^{3}-$ medical students should also apply this principle. Students must protect patient confidentiality by making sure their content ethically adheres to The Healthcare Insurance Portability and Accountability Act. Additionally, students should generally aim to demonstrate the same online etiquette expected of practicing clinicians, such as carefully monitoring account security, following all hospital policies regarding taking pictures and demonstrating respect among colleagues. ${ }^{30}$ Professionalism is one of the standards expected by the Liaison Committee of Medical Education ${ }^{31}$ and the Accreditation Council for Graduation Medical Education ${ }^{32}$ and should be upheld through social media use as well. Medical school curricula and educational professional organizations should emphasize the importance of online professionalism to encourage preprofessional students incorporate such practices. Additionally, students should seek out professional guidelines written by governing bodies that are specifically geared toward social media use throughout medical school.

Medical students must be vigilant about their privacy settings on social media outlets, particularly if discussing details about specific medical schools, residency programs, or hospitals. Public availability of negative discussions may have the potential to harm the integrity and reputation of a potential applicant or an institution itself. 
Social media accounts often express students' individual character and personality through hobbies and microblogging, therefore offering greater insight into a potential residency applicant. In a survey of general surgery programs, residency directors reported frequently viewing the online behavior of residency applicants during the interview process. ${ }^{33}$ By following institutional and public faculty accounts, students can likewise use social media to explore the culture and fit of a residency program and by identifying potential mentors and their career successes. In this context, social media helps strengthen distinct connections by revealing passions and skills relevant to one's career or personal life to others.

Not all educational internet Web sites are created equally; thus, educational social media content needs to be assessed on quality and accuracy. Some previous studies evaluating ophthalmic YouTube videos have found many videos to be misleading. ${ }^{34,35}$ Students should note if the educational content from a social media account is delivered from a well-established medical organization or highly reputable institution whenever possible. For example, Mayo Clinic has published high-quality videos of ophthalmologists providing lectures, patient stories, narrated animations, and research developments. $^{36}$

\section{Future Implications}

Although several professional organizations and journals within ophthalmology have active social media accounts, the authors believe that there remains the potential for growth and enhanced outreach from the ophthalmology community. Medical schools, residencies, and state/national organizations have highly variable engagement with social media, and many of us are missing a critical opportunity to engage with a generation of students who have been brought up on social media. How can we harness social media to broaden our connections with each other?

For students, forming social media groups helps develop shared interests and provide mutual support. Although many medical schools possess specialty-specific clubs, open social media groups dedicated to such clubs may encourage more students within an institution to explore the field. Social media groups can connect aspiring applicants to school alumni who have gone through the application process and are currently involved in ophthalmology. Student-run social media groups have the potential to expand further by connecting with students of other medical schools as well, allowing broader collaborations beyond the walls of a single institution.

For educators and institutions, first and foremost devote resources to social media and form a strategy team. The world of social media is a complex maze, and besides knowing how best you want to engage your audience, it is critical to consider the medicolegal implications of your posts, especially in the era of artificial intelligence where seemingly deidentified data may be identifiable by sophisticated computers. Second, we encourage medical educators and other professional ophthalmologists to team up with medical school and society leadership to spread awareness of both local and external social media sites. Deliberate and thoughtful engagement through social media may allow us to provide mentorship to a larger group of students and is crucial for the continued advancement of the field for future generations.

Social media is not the remedy for limited ophthalmic education in medical schools-ultimately a medical student's initiative and dedication to actively seek out opportunities is still a prerequisite. Nonetheless, social media has expanded the access to communication, networking, and education within ophthalmology available to medical students: the online resources are widely available and do not require large-scale changes to institutional curricula. For ophthalmology as a profession, social media can supply an earlier and more in-depth introduction to a traditionally secluded discipline, and for training programs and ophthalmologists in practice, social media provides multiple avenues to attract the brightest medical minds into the ophthalmic community.

\section{Funding}

None.

Conflict of Interest

None declared.

\section{References}

1 U.S. population with a social media profile 2019. Statista. Available at: https://www.statista.com/statistics/273476/percentage-of-uspopulation-with-a-social-network-profile/. Accessed July 29, 2019

2 Advisory Opinion: Social Media and Professionalism. American Academy of Ophthalmology. Available at: https://www.aao.org/ ethics-detail/advisory-opinion-social-media-professionalism. Accessed July 28, 2019

3 Tsui E, Rao RC. Navigating social media in \#ophthalmology. Ophthalmology 2019;126(06):779-782

4 DeCamp M. Social media and medical professionalism: toward an expanded program. Arch Intern Med 2012;172(18):1418-1419

5 Fenwick T. Social media and medical professionalism: rethinking the debate and the way forward. Acad Med 2014;89(10):1331-1334

6 Gholami-Kordkheili F, Wild V, Strech D. The impact of social media on medical professionalism: a systematic qualitative review of challenges and opportunities. J Med Internet Res 2013;15 (08): 184

7 Andrea Tooley - YouTube. YouTube. Available at: https://www. youtube.com/channel/UCM6Ta_9fGvPHePLcAO5qaLA. Accessed August 26, 2019

8 Andrea Tooley MD. (@dr.andreatooley) - Instagram photos and videos. Available at: https://www.instagram.com/dr.andreatooley/. Accessed August 26, 2019

9 Shah M, Knoch D, Waxman E. The state of ophthalmology medical student education in the United States and Canada, 2012 through 2013. Ophthalmology 2014;121(06):1160-1163

10 Wu DJ, Greenberg PB. A self-directed preclinical course in ophthalmic surgery. J Surg Educ 2016;73(03):370-374

11 Residency and Fellowship Match Services. Ophthalmology Residency. San Francisco Match. Available at: https://sfmatch.org/SpecialtyInsideAll.aspx?id=6\&typ=2\&name=Ophthalmology\#. Accessed July 29, 2019

12 Match Calendars. The Match, National Resident Matching Program. Available at: http://www.nrmp.org/match-calendars/. Accessed August 26, 2019

13 Esparaz ES, Binder SB, Borges NJ. How prepared are medical students to diagnose and manage common ocular conditions. J Educ Eval Health Prof 2014;11:29 
14 Cobbs L, Tsui E, Haberman I, et al. Student perceptions of the ophthalmology curriculum in medical school. J Acad Ophthalmol 2018;10(01):e79-e82

15 Loh AR, Joseph D, Keenan JD, Lietman TM, Naseri A. Predictors of matching in an ophthalmology residency program. Ophthalmology 2013;120(04):865-870

16 Sterling M, Leung P, Wright D, Bishop TF. The use of social media in graduate medical education: a systematic review. Acad Med 2017;92(07):1043-1056

17 Thia BC, Wong NJ, Sheth SJ. Video recording in ophthalmic surgery. Surv Ophthalmol 2019;64(04):570-578

18 Eyetube: Ophthalmic Surgical Video Resource. Available at: https://eyetube.net/. Accessed July 29, 2019

19 Rozenbaum I, Ritch R. Eyetube. Arch Ophthalmol 2009;127(05):648

20 Ophthalmology (@AAOjournal). Twitter. Available at: https://twitter. com/aaojournal. Accessed February 1, 2020

21 The easy way to learn ophthalmology - TimRoot.com. Available at: https://timroot.com/. Accessed January 9, 2020

22 AUPO @aupo.org. Facebook. Available at: https://www.facebook.com/aupo.org/. Accessed November 29, 2019

23 Schechet SA, Pandya HK, Mehta MC. Social media collaboration of retinal physicians: a 'Young Retina Forum' survey. Eur J Ophthalmol 2019:1120672119832186

24 Advocacy Ambassador Program - American Academy of Ophthalmology. Available at: https://www.aao.org/mid-year-forum/advocacy-ambassador-program. Accessed November 16, 2019

25 Mid-Year Forum Overview - American Academy of Ophthalmology. Available at: https://www.aao.org/mid-year-forum/overview. Accessed November 29, 2019

26 \#MyF2019 Hashtag on Twitter. Twitter. Available at: https:// twitter.com/hashtag/myf2019. Accessed November 29, 2019
27 Grubbs JR Jr, Mian SI. Advising students interested in ophthalmology: a summary of the evidence. Ophthalmology 2016;123 (07):1406-1410

28 Xierali IM, Nivet MA, Wilson MR. Current and future status of diversity in ophthalmologist workforce. JAMA Ophthalmol 2016; 134(09):1016-1023

29 Minority Ophthalmology Mentoring Program - American Academy of Ophthalmology. Available at: https://www.aao.org/minoritymentoring. Accessed August 26, 2019

30 Alleje ML, Austria BC, Shrestha PA. Social media etiquette in medicine. Br J Hosp Med (Lond) 2019;80(09):130-132

31 Functions and Structure of a Medical School: Standards for Accreditation of Medical Education Programs Leading to the MD Degree. Liaison Committee on Medical Education. 2019. Available at: http:/ lcme.org/publications/\#Standards. Accessed August 26, 2019

32 Common Program Requirements (Residency): Accreditation Council for Graduate Medical Education. Available at: https:// www.acgme.org/Portals/0/PFAssets/ProgramRequirements/ CPRResidency2019.pdf. Accessed August 26, 2019

33 Langenfeld SJ, Vargo DJ, Schenarts PJ. Balancing privacy and professionalism: a survey of general surgery program directors on social media and surgical education. J Surg Educ 2016;73(06): e28-e32

34 Şahin A, Şahin M, Türkcü FM. YouTube as a source of information in retinopathy of prematurity. Ir J Med Sci 2019;188(02):613-617

35 Bae SS, Baxter S. YouTube videos in the English language as a patient education resource for cataract surgery. Int Ophthalmol 2018;38(05):1941-1945

36 Ophthalmology Videos. Medical Professionals. Mayo Clinic. Available at: https://www.mayoclinic.org/medical-professionals/ophthalmology/videos. Accessed July 29, 2019 